\title{
The impact of real-time computerised video analysis and feedback on hand hygiene practice and technique on a surgical ward
}

\author{
A Ghosh ${ }^{1}$, G Lacey ${ }^{1 *}$, C Gush$^{2}$, S Barnes ${ }^{3}$ \\ From International Conference on Prevention \& Infection Control (ICPIC 2011) \\ Geneva, Switzerland. 29 June - 2 July 2011
}

\section{Introduction / objectives}

The fast hand movement and occlusion of observers' views make it difficult to audit hand hygiene technique. We investigate the effect of computerised video observation and real-time feedback on the hand hygiene technique.

\section{Methods}

Hand wash monitors (SureWash, Ireland) were placed above clinical sinks in a 28 bed surgical ward. The clinical trial consisted four phases: Phase 1 (1 week) determined the baseline practice without any feedback. Phase 2 (4 weeks) provided real-time feedback. In Phase 3 (5 weeks) a printed report was also presented at the weekly staff meeting. In Phase 4 ( 1 week) the feedback was turned off. The feedback was shown on a computer screen of each unit. SureWash deemed a hand washing complete if it followed every step of the CleanYourHands protocol.

\section{Results}

The number of hand wash events (HWE) for each day was divided by the product of the number of patients and staff. The daily averages of HWE were $0.14 \pm 0.01$, $0.36 \pm 0.02,0.35 \pm 0.02,0.18 \pm 0.2$ for phases $1,2,3$ and 4 respectively. The increase between phase 1 and 2 was $156 \%\left(\mathrm{p}<10^{-7}\right)$ and the fall in phase 3 from 4 was $48 \%$ $\left(\mathrm{p}<10^{-4}\right)$. The daily average number of completed HWE was $0.02 \pm 0.004,0.17 \pm 0.01,0.16 \pm 0.18,0.02 \pm 0.005$ in phases 1, 2, 3 and 4 respectively. The increase between phase 1 and 2 was $703 \%\left(\mathrm{p}<10^{-9}\right)$ and the fall in phase 3 from 4 was $48 \%\left(\mathrm{p}<10^{-3}\right)$. The total completion rates were: $15.8 \%$ (38/240), 49.1\% (719/1464). 44.4\% (724/ $1630)$ and $13.3 \%(24 / 180)$ in each phase respectively.

\section{Conclusion}

Real-time computerised feedback on proper technique resulted in a significant increase in the number of HWE $(+156 \%)$ and in the adherence $(+703 \%)$ to the CleanYourHands protocol. Feedback acted as a reminder of technique and provided instruction on "difficult" poses.

\section{Disclosure of interest}

A. Ghosh: None declared, G. Lacey Shareholder of GLANTA Ltd, C. Gush: None declared, S. Barnes: None declared.

\section{Author details \\ ${ }^{1}$ Computer Science and Statistics, Trinity College Dublin, Dublin 2, Ireland. ${ }^{2}$ Department of Health, London, UK. ${ }^{3}$ Mid Essex Hospital Services, \\ Chelmsford, UK}

Published: 29 June 2011

doi:10.1186/1753-6561-5-S6-O52

Cite this article as: Ghosh et al:: The impact of real-time computerised video analysis and feedback on hand hygiene practice and technique on a surgical ward. BMC Proceedings 2011 5(Suppl 6):O52.

${ }^{1}$ Computer Science and Statistics, Trinity College Dublin, Dublin 2, Ireland

Full list of author information is available at the end of the article

(c) 2011 Ghosh et al; licensee BioMed Central Ltd. This is an open access article distributed under the terms of the Creative Commons Attribution License (http://creativecommons.org/licenses/by/2.0), which permits unrestricted use, distribution, and reproduction in any medium, provided the original work is properly cited. 